\title{
Research on the Influence of Economic Globalization on China's Social Welfare Level
}

\author{
Handuo Li \\ Department of Political Economy, King's College, London, UK \\ Email: zhujunmin.2008@163.com
}

How to cite this paper: Li, H.D. (2018) Research on the Influence of Economic Globalization on China's Social Welfare Level. Open Journal of Social Sciences, 6, 201-208.

https://doi.org/10.4236/jss.2018.610016

Received: September 14, 2018

Accepted: October 28, 2018

Published: October 31, 2018

Copyright (c) 2018 by author and Scientific Research Publishing Inc. This work is licensed under the Creative Commons Attribution International License (CC BY 4.0).

http://creativecommons.org/licenses/by/4.0/

(c) (i) Open Access

\begin{abstract}
Since the reform and opening up, China's economy has become more and more integrated into the world wave, and the changes in foreign trade have become more and more large, almost instantaneously changing to be doubled in four years. Based on the information and statistics of the WTO, China is already another major economic breakthrough after the world's largest foreign exchange reserve country and the world's second largest economy. This paper has studied the change of welfare of China and uses the data of people's salary so as to show the relationship between welfare level and governing station. At last, this paper gats the conclusion that China's welfare undertakings must consider the problem of narrowing the income gap. It is necessary to reduce the gaps in regional participation in the context of globalization with appropriate positive measures, so as to better develop the economic level of each region, and strive for coordination in development.
\end{abstract}

\section{Keywords}

Economic Globalization, Social Welfare, Influence

\section{Function Theory of Economic Globalization and Social Welfare}

1) Classical trade theory

Classical trade theory includes two parts: absolute advantage and comparative advantage theory. The absolute advantage theory is based on labor value theory and international division. The theory holds that consuming labor is the benchmark for the cost measurement of goods, while the basis of international trade and the international division of labor determine the absolute difference in labor productivity [1]. Regarding the mode of production and trade under the classical trade theory, it believes that if a country's production cost of a certain commod- 
ity is absolutely lower than that of other countries, then this commodity has an absolute advantage, and the opposite is the absolute disadvantage [2]. If a country wants to achieve better development, it must develop the country's absolute advantage product and specialize in the production of this product. And this theory has a shortcoming, that is, if a country's goods have absolute disadvantages, and another country has the absolute advantage of production, there will be no trade. But in fact, Ricardo continues to develop on Smith's theory of absolute advantage [3]. His view is that the emergence of international trade behavior is based on comparative advantage, not absolute. He believes that even if two commodities in a country are absolutely disadvantage to produce, and another country has absolute advantage, there will still be trade behavior [4].

2) New trade theory and improvement of social welfare

After entering the mid-20th century, with the changes in the international trade situation, new trade theory was created. Because of the shortcomings of traditional trade theory, many economic problems are not well answered, so Paul Krugman and a group of economists built a new analytical framework based on the original theory of international trade, thus generating the trade theory [5]. The theoretical model was constructed on the concepts of incomplete competition, differentiated products and increasing returns to scale. The similarity between the new trade theory and the classical trade theory is that they all think that labor productivity is the basis of the development of international trade. The difference is that the new theory holds that the degree and scale of economic development and economic monopoly are all related factors that lead to trade. Therefore, in terms of trade between two countries, as long as there is no difference in factor endowment, as long as there is economic monopoly and scale economies, trade behavior will occur [6]. The product production and trade model under the new trade theory will form a pair of contradictions. That is, under self-sufficiency, scale economies become different, and the production scale will become smaller as the degree of differentiation becomes more complete, at this time, it is difficult to exert sufficient scale economies effect [1]. However, the emergence of trade not only allows resources to obtain tolerance on restrictions, but also gradually expands the market scale, and will also bring certain benefits to the development space of scale economies, that is, to amplify its differentiated adjustable space [7]. Countries can centralize and specialize in the production of some differentiated commodities, and exchange and acquire through trade activities, thereby improving the level of national social welfare.

3) Social welfare function of new welfare economics

Pareto economics prevailed in the 20th century, and the Pareto standard is at its core. Its standard is to use the ordinal utility to avoid the value judgment problem, so that the problem of economic income distribution is neglected. Pareto Economics believes that the only criterion for judging social welfare is personal welfare, and does not fully elaborate on social welfare [8]. It was not until 1939-1947 that the social welfare function was injected into the Pareto standard, 
and this defect was successfully made up [9]. The view of welfare economics is that the value of production effect variable $z_{i}$ produced by social welfare and all real-valued variables $z$ that may affect welfare are the decisive factors of social welfare value $W$, and the formula is: $W=W\left(z_{1}, z_{2}, \ldots\right)$, however, the social welfare function was not uniformly regulated at the time, and the general function value was usually taken. Later economist Kenneth Arrow tried to set the specific social welfare function for this method, then there is the emergence of the social decision rule function $R=f\left\{\left(R_{\mathrm{i}}\right)\right\}$. The final trial results show that the social welfare function that can meet the four conditions of non-authoritarian, non-relevant choice, non-restrictive domain and Pareto principle does not exist at all [10]. Therefore, this idea was negated and the Arrow's impossibility theorem was established. Social welfare economics was once confused with the emergence of Arrow's conclusions. However, the significance of Arrow's challenge is to question the implications of the new welfare economics, so later the elite social welfare function, and the AmartyaSen and Rawls social welfare functions emerged. Arrow had laid a valuable scientific foundation for their expansion [2].

4) AmartyaSen's social welfare function

Sen's point of view is that Arrow's theorem excludes other forms of social selection rules, so only voting rules are more practical. And because there is a lack of reactional utility in interpersonal comparisons, so there is impossible art. Therefore, Sen believes that social welfare cannot only include personal utility levels, but also needs to add personal welfare to it. For example, ethics such as non-exploitation, abuse, etc., need to be taken into account. Simply using utility as a standard of measure is too general and flawed. Therefore, Sen broke the framework of welfare attention analysis and began to study from non-welfare. He successfully combined the comprehensive investigation of material aspects and freedom of ability, and finally analyzed the social welfare level function, and used the formula $W=y(1-\mathrm{G})$ to measure the impact of economic growth and income disparity on the change of social welfare level, among them, $W, y, \mathrm{G},(1$ - G) respectively represent social welfare level, per capita income, Gini coefficient and income gap. It is easy to see from the comparison of formulas that per capita income has the positive correlation with social welfare, and income gap has the negative correlation with it.

\section{China's Globalization Development Status}

Since the above mentioned GDP per capita and income gap are related to social welfare, then when we explore the impact of economic globalization on the level of social welfare, we will inevitably involve economic and trade issues, so naturally we must began to explore from the specific level of development of China's trade and economy:

China's total foreign trade volume has been growing. Since its accession to the WTO, it has maintained a very high level. In 2013, China's foreign trade volume exceeded the US\$4 trillion mark and became the world's largest trading nation. 
Its growth trend in the world has been obvious, started from the obvious growth since the accession to the WTO in 2001, has maintained a growth trend except for the special year of 2009, but there has been a significant slowdown since 2012. It may be related to the fact that the state after the world economic crisis has not fully recovered, and is also related to the structural adjustment factors of China's internal economy. However, compared with the trade balance, although China's foreign trade has experienced increases of several major surpluses, the overall trend is rising.

In general, China's position in economic globalization is second only to the EU and the United States, it is the third largest provider and consumer of goods and services. Trade growth has also maintained a double-digit growth rate. It can be said that it is among the fastest growing countries in the world in terms of growth rate. Since 2012, the net inflow of FDI has begun to decline, and it has become the FDI inflow country second to the EU. It can be said that China is a well-deserved country with the largest net inflow of FDI in Asia, no matter from which aspect, the world economy develops is inseparable from China's participation, China plays a pivotal role.

The development of China's trade has led to an increase in trade volume in the eastern, central and western regions of China, from a comparative perspective, the differences between the eastern, central and western regions of China is still very large. Especially in the contrast between the central and western regions, the central trade volume is always much higher than that in the west. However, with the change of growth of foreign investment in China, the eastern, central and western regions have also formed a certain growth contrast in the use of foreign direct investment. From the perspective of regional comparison, the eastern region has always maintained a large proportion of foreign direct investment, although there have been many cases of from increase to decrease in the process, however, if compare the central and western regions, the central region is larger than the western region. Regardless of the angle, China's role in the globalized economy cannot be ignored, from an economic perspective, the link between China and the world is inseparable and will inevitably have a major impact. So in terms of this impact, how China should look at the actual impact of economic globalization on itself, various effects including social welfare, is a topic we should focus on.

\section{Empirical Study of Influence of Economic Globalization on Social Welfare}

1) Selection of social welfare function

Based on the impact of economic globalization on China's social welfare, it is necessary to extract the social welfare function and then draw conclusions through model comparison. Therefore, this paper needs to choose AmartyaSen as the research tool of social welfare function, and explore the specific process from the formula $W=y(1-\mathrm{G})$, by fitting the income decision function, in the 
social welfare function, the economic globalization factor is introduced and calculated, and a representative China social welfare impact model is obtained. We can see from the formula that Sen's understanding of the social welfare function is: a society created wealth of a country in a period of time, can be expressed by economic growth. These material foundations are places where members of society obtain material access. In other words, the more social wealth, the more members of society can obtain material foundations. This is also a direct response of the ability to acquire material of members of society, and social welfare is relatively high [3]. The income gap is a reflection of the universal access ability of members of society to obtain to material. If there is a large income gap between members of society, then the ability of these members to acquire material is relatively low, the lower the freedom degree, the lower the level of social welfare.

2) Setting model and calculation method

a) Data processing

Per capita income is calculated by the weighted calculation of urban and rural population through non-agricultural and agricultural per capita income data. Data on rural and urban per capita income are obtained through inflation reduction using the GDP deflator. Population burden rate = (total population employed population)/(employed population) $\times 100 \%$. Gov (government economic expenditure) is obtained by means of financial expenses in each region minus the expenditure management fee. FDI is to extract the per capita value and refer to the exchange rate intermediate price of the corresponding year of the "China Statistical Yearbook", usually the unit is RMB, so it needs to be converted. Trade value is expressed in terms of the per capita trade amount ratio, and is also based on the RMB conversion unit in the "China Statistical Yearbook". The ratio of urbanization (Urb) is based on non-agricultural or total population.

b) Model formula verification

In the model verification, this paper selects the social welfare function formula of Nobel Prize winner AmartyaSen to carry out the effect measurement of economic globalization on the social welfare. The following is the specific measurement process:

$$
W=y(1-\text { Gini })
$$

In the formula, social welfare and per capita income is respectively $W$ and $y$, and measure of fairness is (1-Gini), which is as the standard coefficient. We can perform the formula calculation of social welfare by fitting the decision function of $y$. Because this formula is responsible, it contains a variety of factors, such as the economic globalization function. Therefore, we can substitute the FDI representing the value of the economic globalization variable into the above formula, that is, $W=$ FDI (which can also be a trade function), and use the derivative method to calculate the marginal contribution to $W$ produced by the two variables. Then, with the social welfare function of $W=y(1-$ Gini $)$ to ob- 
tain, if among the social welfare influence factors, the influence of a certain factor is proportional, then $\partial W / \partial x>0$.

So the income decision model at this time is:

$$
Y^{(\theta)}=a_{0}+a_{1} X_{1}^{(\theta)}+a_{2} X_{2}^{(\theta)}+\ldots+a_{K} X_{K}^{(\theta)}+u
$$

Then the conditions for the proportional influence of this factor on social welfare can be written as:

$$
a_{i}(1-\text { Gini }) X^{(\theta-1)}-\partial \text { Gini } / \partial x>0
$$

The calculation of the Gini coefficient for the inter-regional income gap measure should be:

$$
\text { Gini }=\sum\left(A_{i} \times y_{i}\right) / Y
$$

Then you can know:

$$
\partial \text { Gini } / \partial y_{j}=A_{j} / Y-\sum A_{j} y_{j} /(Y)^{2}=\left(A_{j}-\text { Gini }\right) / Y
$$

Here, $Y$ represents the sum of per capita income $\left(y_{i}\right)$ of 29 provinces in a certain year, so the judgment conditions in the above formula (1) can also be expressed as follows:

$$
a_{i}(1-\text { Gini }) X^{(\theta-1)}-\sum\left\{\left[\left(A_{j}-G i n i\right) / Y\right]\left(a_{i} \times y_{j}^{(1-\theta)} \times x^{(\theta-1)}\right)\right\}>0
$$

We only need to substitute the inter-provincial data of China from 2001 to 2014 into the formula calculation. From the calculation of this formula, we can draw the marginal effect of trade and FDI on China's social welfare. By summing up the data, we can get the social welfare data impacted by economic globalization required by the project.

3) Analysis of results

In order to more intuitively show the impact of economic globalization on China's social welfare, the author deliberately extracted the data from 2001-2014 in China to make a visual form, as follows (Table 1).

We can see from the table that economic globalization has not shown much overall effect on inter-annual changes in China's social welfare, and the figures

Table 1. Data from China's central government.

\begin{tabular}{cccccccc}
\hline Year & Trade & FDI & Total effect & Year & Trade & FDI & Total effect \\
\hline 2001 & 0.00028 & 0.00098 & 000126 & 2008 & 0.00011 & 0.00041 & 0.00052 \\
2002 & 0.00029 & 0.00080 & 0.00109 & 2009 & 0.00014 & 0.00042 & 0.00056 \\
2003 & 0.00022 & 0.00075 & 0.00097 & 2010 & 0.00011 & 0.00037 & 0.00048 \\
2004 & 0.00018 & 0.00073 & 0.00091 & 2011 & 0.00010 & 0.00038 & 0.00048 \\
2005 & 0.00016 & 0.00067 & 0.00083 & 2012 & 0.00008 & 0.00038 & 0.00046 \\
2006 & 0.00014 & 0.00053 & 0.00066 & 2013 & 0.00007 & 0.00032 & 0.00040 \\
2007 & 0.00012 & 0.00045 & 0.00057 & 2014 & 0.00009 & 0.00056 & 0.00061
\end{tabular}


are all above 0 , indicating that for China's social welfare improvement, participation in economic globalization is helping its growth. Since 2001, the welfare level has risen, and in recent years there has been a fall, although the trade impact of China has also decreased, the state has been relatively stable on average. The year-on-year growth of FDI in China also affects China's welfare level. This is because China was relatively poor at the beginning of reform, and the lack of capital gave the society a strong demand for capital development. The injection of foreign capital solved the problem of China's lack of funds and greatly promoted China's economic growth, therefore, economic globalization has an enhanced role and influence on the country's social welfare.

\section{Conclusion}

This paper demonstrates the multi-faceted effects of economic globalization on China's social welfare, and specifically analyzes China's positive improvement strategies in this regard. In the new era, China should also focus on reform and opening up, promote the combination of "introduction" and "going out" and actively participate in international competition. In this process, we must not neglect the positive impact of economic globalization on China's social welfare. We must raise the level of per capita economic income on the basis of clearly understanding the two concepts of economic globalization influence and social welfare. At the same time, we must ensure the quality of the global economic participation, strengthen our international competitiveness, increase the unit participation strength of globalization, and maintain the continuous growth of per capita GDP. In addition, in the context of the economic global society, China's welfare undertakings must consider the problem of narrowing the income gap. It is necessary to reduce the gaps in regional participation in the context of globalization with appropriate positive measures, so as to better develop the economic level of each region, strive for coordination in development.

\section{Conflicts of Interest}

The author declares no conflicts of interest regarding the publication of this paper.

\section{References}

[1] Sheng, B. and Wei, F. (2013) The Impact of Foreign Direct Investment on China's Urban-Rural Income Gap: An Empirical Test of China's Provincial Panel Data. Contemporary Finance and Economics, 13, 39-52.

[2] Zhang, X. and Zhao, S.Q. (2013) Research on the Relationship between Foreign Trade Development and China's Regional Income Disparity. Economic Issues, 11, 66-68.

[3] Shen, G.L. and Song, F.Z. (2014) The Influence of FDI on China's Income Distribution Gap and Countermeasures-An Empirical Study Based on Multidimensional Variables. World Economic Research, 11, 15-17.

[4] Mai, L.U. and Feng, M. (2010) Reforming the Welfare System in the People's Re- 
public of China. Asian Development Review, 25, 58-80.

[5] Guo, J.L. (2013) Political Economy of Welfare Structure Differences in China's Developed Regions-A Comparison of Liaoning, Zhejiang and Guangdong Provinces. Journal of Shaanxi Academy of Governance, 3, 73-77.

[6] Röhrs, S. and Winter, C. (2011) Wealth Inequality and the Optimal Level of Government Debt. ECON-Working Papers.

[7] Yang, S.W. and Qi-Quan, X. (2016) A Probe into the Moderation of China's Agricultural Market Opening. Journal of South China Agricultural University, 1, 27.

$\mathrm{Xu}$, J. (2014) The Implementation and Development of Child Welfare and Protection Works in China. China Journal of Social Work, 7, 318-322. https://doi.org/10.1080/17525098.2014.962762

[8] Tang, J. (2014) Rcep: Integration Dilemma and Impact on China's Economic Welfare and Industries. Finance \& Trade Economics, 35, 85-93.

[9] Adams, J. and Hannum, E. (2010) Children's Social Welfare in China. Reap Papers.

[10] Li, Z.L. (2014) Economic Growth, Social Welfare and Citizen's Satisfaction with Local Government-Evidence from China's Minimum Living Support Scheme (MLSS). 2014 America Sociology Association Annual Meeting, San Francisco, 16-19 August 2014. 